\title{
Effective Continuing Education for Training the Archivist
}

\section{PAUL CONWAY}

\begin{abstract}
This paper argues for the intimate linkage between the effectiveness of continuing professional education programs and systematic evaluation. After briefly describing the context of existing continuing education offerings for archivists, the article describes the evaluation-effectiveness link by reporting briefly on the work of educational evaluation theorists. It concludes with practical suggestions for designing an effective evaluation program.
\end{abstract}

ARCHIVISTS NEED a comprehensive view of the role of continuing professional education in helping them do their jobs. Ideally, such a view would distill the essence of twenty-five years of innovative research and thinking on educational effectiveness and place this knowledge within the context of professional archival practice. The author would draw conclusions about the most appropriate ways to structure a continuing education program, to present complex subject matter to a diverse audience, and to evaluate the success of the program in accomplishing its goals. In short, such a magnum opus would be concerned primarily with cause and effect and the transfer of a body of knowledge.

The goals of this article are considerably more modest, focusing instead on educational evaluation as a necessary research process. After briefly describing the continuing education context for archivists, the article will describe the essential link between the objectives of a continuing education program and the purpose of the program's evaluation. This linkage raises for the archivist a number of important issues that point toward appropriate approaches to the evaluation process. The article concludes with some practical recommendations that should be kept in mind when developing an evaluation program. The ultimate point of the

Paul Conway heads the Preservation Department at the Sterling Memorial Library, Yale University. 
paper is that evaluation is a waste of resources unless the effort fits the situation and the findings are used by those who either conduct or authorize the evaluation to improve programs and services.

\section{Archival Education Context}

Professionals have three environments in which to acquire the information to do their jobs: formal coursework in universities and colleges, on-the-job training experiences, and workshops or other instructional programs usually offered by specialists outside the work context. The standard notion of professional education arranges these three environments in a linear time line. Namely, individuals seeking a professional career first pursue the recognized entry-level degree, which may range from a bachelor's degree with a specialized major, one of several master's-level degrees, or professional advanced degrees such as the J.D. or M.D.

After acquiring the ticket, they are trained on the job in the specific technical or administrative procedures appropriate to the organization in which the person is employed. Finally, as their career needs dictate, professionals seek specialized continuing education to maintain or broaden skills. In this stereotype, the life-long responsibility for learning begins and ends with the individual.

It is important to recognize that, for a variety of reasons whose elaboration is outside the scope of this paper, most archivists do not follow a linear path to professional growth. The findings of a recent survey of Society of American Archivists (SAA) members calls into question the viability of the concept of the history master's or the M.L.S. as the entry-level degree. ${ }^{1}$ People who consider themselves a part of the archival profession and who are sufficiently committed to join the profession's only national association simply start working in an archival repository and increase the full variety of their educational experiences as they work their way up the ranks of the organization or gain additional years of experience.

In the current environment the distinction between archivists who possess a particular advanced degree and those who have garnered critical work experience but who may lack a designated educational credential is artificial. This situation may actually be an advantage for the archival profession. In a fluid environment, faculty, adjunct instructors, professional association managers, archival administrators, and others who wish to design curricula are free to take maximum advantage of the wide range of individual experience, including preprofessional experience, and integrate more fully formal academic degree programs with continuing professional education.

In the past fifteen years especially, archivists have had numerous opportunities to attend continuing education programs. A ten-year compilation, prepared in 1988, of SAA workshops, limited enrollment seminars, and preconference workshops, lists 246 separate programs. 
Although almost one in five of these courses was in the areas of preservation and conservation, the variety of discrete programs is impressive. Since 1988, SAA has sponsored almost one hundred additional programs. ${ }^{2}$ Currently many other opportunities for continuing education exist, few of which are listed in the new SAA education directory. The range includes one- and two-week institutes, workshops at regional archival association meetings, state-wide training programs supervised by some state government archives, and special offerings from some of the larger archival repositories in the United States. ${ }^{3}$

Existing literature on continuing education in the archival context is extraordinarily weak, given the proliferation of course offerings. Very little thinking on needs, priorities, or methodologies is in the published record of the past decade. Mary Jo Pugh's unpublished discussion paper prepared for a 1987 conference on archival education is one of the only statements on priorities. Her comments reflect responses to a survey of archivists on appropriate course topics, but they lack an overall framework within which continuing education programs can be developed and evaluated. ${ }^{4}$ Similarly, a recent unpublished paper on SAA's continuing education program focuses more on organizational limitations than on the needs and opportunities for developing an innovative and comprehensive set of programs. ${ }^{5}$

\section{Continuing Education and Evaluation}

The weakness of the educational framework within the archival community makes educational evaluation far more complicated than it could be if overall goals and objectives were articulated by those most responsible for monitoring progress in the field. This is because the objectives of educational evaluation are fundamentally linked to the goals of the educational program being evaluated. In general, there are five possible goals of a continuing professional education program, listed here in order of increasing sophistication:

1. broad participation;

2. personal growth;

3. acquisition of knowledge, skills, or aptitudes;

4. performance improvement; and

5. organizational development.

The first goal is limited to getting people in the door. Goals two through four are oriented largely toward the individual learner. Library management specialist A. J. Anderson describes the personal challenges of innovation when he states his opinion that ". . . some people can change certain aspects of themselves and their behavior if they want to badly enough and if they are willing to work hard enough at it." ${ }^{\text {" It is not }}$ necessarily the responsibility of archival educators either to recruit participants or to ensure their personal fulfillment, especially given the many barriers to personal growth and performance. 
The fifth goal, organizational development, transcends individual needs to recognize that professionals generally work together in an organizational setting. Given the significant monetary and human resource demands that the development of effective continuing education programs place on those who design and implement such programs, the most important goal for educational programs is institutional development via the application of new knowledge. Practice changes because one or more archivists choose to innovate within their institutional context.

The direct link between innovative practice and continuing professional learning was identified many years ago by educational theorist Cyril Houle. He has written that in times of rapid change, when an organization-even an entire profession-is on an uncharted course of action with few reference points to guide it, acquiring and using new information in creative ways becomes all the more necessary. Houle recognizes the essential judgmental character of practical innovation and the accompanying need for measurement, evaluation, and self-assessment. ${ }^{7}$

Continuing professional education in some form is necessary to avoid professional obsolescence. "It is generally assumed that a practitioner who does not keep up with new research findings each year becomes obsolete at the same rate as the knowledge increases," writes Alan Knox. ${ }^{8}$ His assertion, supported by a diverse range of research findings, suggests that the most pressing needs for continuing education for archivists are in areas where the knowledge base is undergoing rapid change, including preservation management, information technology, and descriptive standards. Similarly, if archivists are concerned that continuing education should respond to the challenge of professional competence and to the dangers of professional obsolescence, then the limited resources available to support serious evaluation efforts should be devoted to understanding how new ideas and new techniques are diffusing through the archival profession. To date, these efforts have barely begun.

British researcher Michael Eraut directly addresses the issue of the ways professional knowledge is created and used. Beginning with the hypothesis that "both the ongoing development and the diffusion of good practice depend on the capacity of mid-career professionals to continue learning both on and off the job," Eraut distinguishes between traditional academically derived knowledge (which uses discipline-based theories to derive generalizations and practical principles) and practical knowledge (which may be either codifiable or expressed only in practice and learned with experience). He outlines four possible ways in which knowledge is obtained and used later in life: replicatively (rote repetition), applicatively (rule matching), interpretively (intellectual transformation), and associatively (intuition). ${ }^{9}$

Interpretive knowledge, which requires intellectual effort and an encouraging work environment to apply, is the most important form of general practical knowledge for professionals, and the one that continuing 
education should seek to reinforce. Eraut illustrates this sometimes indirect connection between learning and information use by example:

If somebody encounters a new idea in a lecture, book or seminar and then later refers to it in an essay or project, can we say that the learning takes place only at the moment of the original encounter? Some learning is associated with new input, some with new use; and some, no doubt, with the period in between when there may be reflection on input or contemplation of use. Not only does an idea get reinterpreted during use, but it may even need to be used before it can acquire any significant meaning for the user. ${ }^{10}$

Eraut's practical example is reflected in the sophisticated diffusion of innovation concepts of Everett Rogers and his fellow communication theorists. Diffusion is the process by which an innovation is communicated through certain channels over time among the members of a social system. ${ }^{11}$ An innovation may be an idea, a technique, or a technology. In organizational contexts, Rogers documents how an innovation is transformed as it diffuses; the adopter reinvents the innovation to fit local needs. During implementation an innovation first becomes part of the organization's agenda, then is matched with a specific problem at hand, redefined or reinvented, clarified as a viable practice, and finally made a routine part of the organization's operation. ${ }^{12}$ The reality of reinvention requires that the evaluator not expect that the lessons imparted in the education program will have a direct impact on institutional practice. The evaluator's goal should be to understand how archivists adapt generalized practical knowledge to meet their own needs.

Sophisticated information may be available on changing and improving archival practice, but it will not have significant impact if it is not actively acquired and used by archivists. Charles O'Reilly, a specialist in organizational behavior, has developed an approach to understanding this dilemma. He has found that information will be more likely used when it originates from a powerful, exclusive source and when it is targeted to specific problems in a supportive manner. He proposes that decision makers are led toward preferences for information from particular channels that may be characterized as accessible and trustworthy and that provide condensed treatments of complex issues. ${ }^{13}$

There are significant implications for the design and evaluation of archival education programs when the goal is to ensure that practical theory is acquired and used in institutional settings. "An essential aspect would be to create situations where practitioners, in the relative safety of the classroom, come to see their practice as problematic and are supported in subjecting it to serious scrutiny and theoretical review." 14 This approach would facilitate the development of what Chris Argyris and Donald Schön calls "double-loop learning" and the ability to use experience productively. In double-loop learning, the failure to achieve the intended consequences leads to reflection on the original goal and the setting of a different problem. It is the psychological corollary to the practical reinvention concepts outlined by diffusion theorists. ${ }^{15}$ 


\section{Approaches to Evaluating Educational Effectiveness}

Educational evaluation can be one of the most significant mechanisms for monitoring the adoption of new professional knowledge and practice by archival institutions, not merely for determining whether a particular program works or whether individual participants are immediately satisfied with the program structure and content.

Evaluation is the act of rendering judgments to determine the value (worth or merit) of some treatment or plan that has been tried or put into effect. ${ }^{16}$ W. Edwards Deming identifies four requirements for an effective system of evaluation.

1. meaningful operational measures of success or failure,

2. reasonable research designs for gathering information (data),

3. valid methods for interpreting and presenting the information, and

4. authorized persons to take action on the findings.

The fourth requirement, action, is the most important, for evaluation for its own sake, out of curiosity, or to satisfy someone else's expectations other than those responsible for implementing the educational program, is a waste of everyone's time and money.

Evaluation is also disciplined inquiry that produces new knowledge. Lee Cronbach asserts that external "objectivity" is far less significant to the credibility of the evaluation than profession-wide arrangements that ensure the evaluator's freedom to be honest. David Deshler adds to this perspective by outlining the natural contradiction between the imperatives of valid evaluation and resistance to organizational change. "The paradox ... is that often the organization most in need of change is the organization most resistant to evaluation."17

Gerald Zaltman, a pioneer in the systematic study of organizational change, has defined resistance as not merely the lack of acceptance or the opposite of acceptance of new ideas, but more broadly as "any conduct that serves to maintain the status quo in the face of pressure to alter the status quo." $18 \mathrm{He}$ and his colleagues have outlined a variety of cultural, social, organizational, and psychological sources of resistance to change. Educators committed to continuing professional education that fosters organizational development must be aware of these contexts when designing programs and evaluating them. ${ }^{19}$

Not all continuing education programs are amenable to evaluation from this broad perspective. For programs with more limited goals, more simple and straightforward approaches geared to the specific objective may be appropriate. If the goal of the program is to get people in the door, gate counts matched against professional directories may suffice. If the goal is personal growth, measuring the immediate reactions of the participants, including their satisfaction with the content and presentation of the program, may be adequate. If the goal is knowledge 
acquisition, why not test participants before and after the program and be done with it?

Assessing the achievement of short-term improvement of job performance requires that evaluators work closely with managers and supervisors on an individual basis. A simple cause-and-effect model of the impact of education on performance will be misleading in this regard. Some researchers warn against the strong tendency to rely on a single concept, such as participant satisfaction, to predict potential impact. "A one variable research model is inadequate for explaining the relationship between continuing education and performance. Unless researchers begin to address the complexity of this relationship, they will continue producing results that contribute negligibly to understanding how to plan programs that change performance."20

Determining whether a program can be evaluated from complex perspectives is referred to as evaluability assessment. The technique was pioneered by Joe Wholey and codified in the past fifteen years by a variety of researchers. Evaluability assessment is the process of assessing whether a program is structured and implemented to permit evaluation and also to determine the feasibility of conducting an evaluation given the purpose of that evaluation and the resources devoted to the evaluation project. ${ }^{21}$

Evaluability assessment is a critical requirement, except in those currently rare situations where a specific evaluation strategy has been designed as an integral part of the educational program. The process often finds that programs suffer from vague, unrealistic, or conflicting goals; implementation failures; unintended effects on participants; and varying perceptions by managers and educators of the focus of the evaluation. When such matters are identified early enough in the life of the program and prior to undertaking a formal evaluation, it is often possible to improve the scope and definition of the program. Additionally, evaluability assessment may identify serious methodological issues or constraints on the availability of data that may prohibit the kind of evaluation originally intended by the program designers. Again, if these issues are identified relatively early in the life of the program, it may be possible to take corrective action.

Too much attention has been given in educational evaluation to worrying about whether programs have been delivered as intended, and not enough attention has been given to understanding the process of implementation. In this context, successful evaluation in practice depends on theory, or the construction of "plausible and defensible models of how programs can be expected to work before evaluating them."22

Any number of approaches can be taken to designing an effective evaluation of an ongoing continuing education program whose purpose is to influence archival program development, which is the most significant and worthy goal of continuing professional education programs. Evaluators Blaine Worthen and James Sanders have developed one useful 
scheme for categorizing and describing the six major approaches to evaluation design. The approaches are arranged roughly along a line from objectivity, in a scientific sense, to subjectivity, which appeals to experience rather than the scientific method. ${ }^{23}$ The six major approaches are:

1. objectives-oriented, where the focus is on specifying goals and objectives and determining the extent to which they have been attained;

2. management-oriented, where the central concern is on identifying and meeting the informational needs of managers;

3. consumer-oriented, where the goal is to develop evaluative information on educational products for use by educational consumers in choosing among competing curricula, instructional products, etc.;

4. expertise-oriented, where the approaches depend primarily on the direct application of professional expertise to judge the quality of educational endeavors;

5. adversary-oriented, where planned opposition in points of view of different evaluators is the central focus of the evaluation; and

6. naturalistic- and participant-oriented, where the participation of stakeholders in that which is evaluated is involved in determining the values, criteria, needs, and data for the evaluation.

Determining the most appropriate approach toward evaluation of archival continuing education and coming to terms with all of the assumptions and methodological issues surrounding each approach are the most significant and challenging components of evaluation design.

\section{Recommendations}

This article has suggested areas where rigorous attention needs to be given to the design and implementation of educational programs so that they may be evaluated effectively. A number of specific recommendations are offered toward this end:

1. The goals and objectives of a continuing education program must be defined in measurable terms.

2. The overall population to which the conclusions of the study will be applied should be defined clearly in advance. For example, is the target population all archivists in the United States or only participants in the program?

3. The unit of analysis should likewise be identified fairly early in the process. Is it the individual participant, his or her institution, or something else?

4. Consistent and thorough documentation should be compiled about the participants in the evaluation program. Typically this information is gathered as part of the application process, but it may also be gathered after the fact.

5. Even more important, if the goal of the evaluation is to assess the application of information, it is crucial that detailed information on the institutional settings is compiled. These details should be 
specifically related to the content of the program and the nature of expected improvements.

6. Effort should be devoted to learning about the motivations of participants for enrolling in the program. What did they expect to accomplish? Were they coerced to attend? How much effort was expended to apply and to travel? What are the expectations of supervisors?

7. The nature of the data required to conduct a meaningful evaluation should be identified when the educational program is designed. Similarly, the method for gathering and analyzing this data should be decided in advance. For example, significantly different challenges are presented by quantitative statistical methods and qualitative case-study methods.

8. The role of evaluator as change agent should not be underestimated. The process of gathering and assessing organizational development often forces managers to ask themselves new questions. If the evaluation process is cooperative and interactive, and if the perceptions and attitudes of those being evaluated are considered sensitively, evaluation can reinforce lessons initially imparted in the educational program itself.

\section{Conclusion}

Cyril Houle once characterized continuing professional education as shouting out the window. He wrote, "Much of the ballooning effort labeled 'continuing education' is still characterized either by eager directness and naive faith or by an apparent belief that only marginal efforts and uninspired instruction are needed to bring practitioners to ever higher levels of performance." ${ }^{24} \mathrm{He}$ and others have found these faiths to be misplaced.

The same critique may also be applied to the stunning lack of meaningful evaluation of our educational efforts. If we fail to learn the best ways to bring about constructive improvements in archival programs via the mechanism of continuing professional education programs, then our educational efforts may be analogous to the proverbial tree falling in the forest. Without measurable improvement in archival programs and practice, did the educational experience ever happen?

\section{References and Notes}

1. Paul Conway, "Membership Survey Results," SAA Newsletler 3 (Jan. 1992): 9.

2. Society of American Archivists, Education Office, SAA Workshops-1978 101987 (The Society, 1988). Photocopy.

3. SAA Directory of Archival Education, 1991-1992 (Chicago: Society of American Archivists, 1991).

4. Mary Jo Pugh, "Priorities for Continuing Education," unpublished paper prepared for the SAA Education Conference, Savannah, Ga., Feb. 13, 1987.

5. Donn C. Neal and Jane Kenamore, "SAA Continuing Education: Current Status and Recommendations for Future Development," unpublished report (Jan. 1991).

6. A.J. Anderson, "Do People Change Their Management Styles and Practices as a Result 


\section{Effective Continuing Education for Training the Archivist}

of Taking Courses and Attending Workshops?" Journal of Library Administration 6 (Winter 1985/86): 3. 294.

7. Cyril O. Houle, Continuing Learning in the Professions (San Francisco:Jossey-Bass, 1980),

8. Alan B. Knox, "The Nature and Causes of Professional Obsolescence," in The Evaluation of Continuing Education for Professionals: A Systems View, ed. P. LeBretton (Seattle, Wash.: Univ. of Washington, 1979), 139.

9. Michael Eraut, "Knowledge Creation and Knowledge Use in Professional Contexts," Studies in Higher Education 10 (1985): 121.

10. Michael Eraut, "What is Learned in In-Service Education and How? A Knowledge Use Perspective," British Journal of In-Service Education 9 (1982): 13.

11. Everett M. Rogers, Diffusion of Innovations, 3d ed. (New York: Free Pr., 1983), 5.

12. Ronald E. Rice and Everett M. Rogers, "Reinvention in the Innovation Process," Knowledge: Creation, Diffusion, Utilization 1 (June 1980): 501.

13. Charles A. O'Reilly III, "The Use of Information in Organizational Decision Making: A Model and Some Propositions," Research in Organizational Behavior 5 (1983): 119.

14. Robin S. Usher and Ian Bryant, "Re-examining the Theory-Practice Relationship in Continuing Professional Education," Studies in Higher Education 12 (1987): 210.

15. Chris Argyris and Donald A. Schön, Theory in Practice: Increasing Professional Effectiveness (San Francisco: Jossey-Bass, 1974).

16. Two good definitions are in W. Edwards Deming, "The Logic of Evaluation," in Handbook of Evaluation Research, eds. Elmer L. Struening and Marilynn B. Brewer (Beverly Hills, Calif.: Sage, 1987), 91-105; and Blaine R. Worthen and James R. Sanders, Educational Evaluation: Alternalive Approaches and Practical Guidelines (New York: Longman, 1987).

17. David Deshler, “An Alternative Approach to Evaluation in Continuing Education," in Evaluation for Program Improvement (San Francisco: Jossey-Bass, 1984), 10.

18. Gerald Zaltman, Strategies for Planned Change (New York: Wiley, 1977), 63.

19. Sara F. Fine, "Technological Innovation, Diffusion and Resistance: An Historical Perspective," Journal of Library Administration 7 (Spring 1986): 83-108.

20. Ronald M. Cervero, Suzanne Rottet, and Katherine H. Dimmock, "Analyzing the Effectiveness of Continuing Professional Education at the Workplace," Adult Education Quarterly 36 (Winter 1986): 78-85.

21. Leonard Rutman, Planning Useful Evaluations (San Francisco: Jossey-Bass, 1980), 37.

22. Huey-Tsyh Chen and Peter H. Rossi, "Evaluating with Sense: The Theory-Driven Approach," Evaluation Review 7 (June 1983): 285.

23. Worthen and Sanders, Educational Evaluation, 60-61.

24. Houle, Continuing Learning, 266. 